\title{
Crisis financiera y estructural de Tailandia
}

$\mathrm{E}$ 12 de julio de 1997, tras haber sorteado las olas del ataque especulativo en contra de su moneda, el Banco de Tailandia anunció que no intervendría más en los mercados extranjeros y que permitiría al baht buscar su equilibrio de libre mercado en relación con el dólar americano.

A lo largo de diez años, el baht había sido pagado al dólar a una tasa de aproximadamente 25 a 1 , y este cambio, informal aunque oficial, fue de tal manera central en la política económica que se convirtió en una doctrina. De hecho, esta tasa de cambio representó un símbolo tanto de estabilidad como de dinamismo en el "quinto tigre de Asia”. Así, cuando en cuestión de días el baht flotó con veloz tendencia descendente, perdiómás de 20 por ciento de su valor, $\mathrm{y}$ asestó un tremendo golpe psicológico a toda la nación. Un mundo llegaba a su fin.

Ese mundo, nacido a fines de la década de los cincuenta y cuya fase más espectacular fuera la llamada “época de oro”, se desdobló entre 1986 y 1996.

Antes de la recesión Tailandia había disfrutado de dos décadas de rápido desarrollo; en los sesenta, su crecimiento anual promedio fue de 8 por ciento, de 7 en los setenta y de entre 4 y 6 por ciento en los primeros años de los ochenta, cuando la recesión sacudió al país.

Pero entre 1985 y 1995, cuando las exportaciones se convirtieron en el motor de la economía, Tailandia creció a un ritmo de 10 por

* Investigadora de la Universidad de Keio, Campus Fujisawa, Japón. ciento anual: "el incremento más rápido del mundo", de acuerdo con el Banco Mundial. Había sido en los primeros años de la década de los noventa cuando el país fue bautizado como el "quinto tigre de Asia".

El período de 1986 a 1996 marcó también la cada vez más creciente autonomía en los negocios, que escaparon de las manos de los patrones lo mismo que de los grupos burocráticos y militares; dicho de otra manera, estaba llegando a su fin la política burocrática. Las asociaciones empresariales surgieron como poderosos cabilderos. Los hombres de negocios tailandeses se convirtieron en eficaces actores de la política parlamentaria e hicieron hábil uso de ella; el sector privado fue entonces un paraíso para los talentosos tecnócratas, que fluctuaban entre los negocios y la política. El resultado de todo ello fue un cambio en el equilibrio de poder entre el sector privado y el gobierno, dentro del que el primero actuaba como figura principal.

A pesar de los cambios en la política parlamentaria, todavía a principios de 1996 la prensa mundial ensalzaba al país. Quizá lo más significativo para el gobierno tailandés había sido el anuncio del Banco Mundial en el sentido de que la economía de Tailandia, con 10 por ciento anual, había sido la de más rápido crecimiento del mundo entre 1985 y 1995 . A fines de este último año el octavo Plan Nacional de Desarrollo proyectaba que para 2020 la economía tailandesa sería la octava más grande del globo, con un ingreso promedio per cápita no menor a los 300000 baht, o alrededor de 12000 dólares, a precios constantes de 1993. 
Cuadro 1

Indicadores económicos críticos de Tailandia y sus vecinos del Sudeste Asiático

en vísperas de la crisis financiera asiática de 1997

\begin{tabular}{|c|c|c|c|c|}
\hline & Tailandia & Malasia & Indonesia & Filipinas \\
\hline$\%$ de déficit del PIB & 8.2 & 7 & 3.5 & 4.3 \\
\hline Crecimiento de exportaciones en 1996 & 0.8 & -0.2 & 7 & 24 \\
\hline Deuda externa (billones de dólares) & 89 & 36 & 109 & 42 \\
\hline Deuda del sector privado como \% de deuda externa & 80 & 33(a) & 50 & 35 \\
\hline Deuda de corto plazo como \% de deuda externa & 50 & $21(a)$ & 29 & 17 \\
\hline Bienes raíces y préstamos de ellos & 50 & 21 & 29 & 17 \\
\hline como \% de exposición de bancos comerciales (b) & $15-20$ & 20 & $20-25$ & $15-20$ \\
\hline
\end{tabular}

Notas: (a) 1995

(b) Estas figuras son generalmente subestimadas, ya que muchos préstamos tornados de categorías

distintas a los bienes raíces, como la manufactura, fueron utilizados por el sector de bienes raíces.

Fuentes: Asian Development Bank, International Monetary Fund, Goldman Sachs, Moody's International

Investor Service, Banklo Sentral Pilipinas, Bank of Thailand, Bangkok Bank, entre otros.

La proporción de población viviendo por debajo de la línea de indigencia se reduciría a menos de 5 por ciento, y el resultado sería una amplia mejoría en la calidad de vida de la gran mayoría del pueblo tailandés.

Junto con la reorientación hacia la promoción de las exportaciones, una razón clave para el explosivo crecimiento de Tailandia desde mediados de los ochenta fue el papel jugado por el capital extranjero. A finales de esa década, el enorme flujo de inversiones extranjeras directas había inundado al país y se mantuvo a pesar de las restricciones acerca de la impunidad del capital extranjero en el mercado interno.

Entre 1985 y 1990 las inversiones extranjeras directas ascendieron de 178 millones de dólares a 2200 , y el grueso de ellas estaba representado por la inversión japonesa, que aumentó de 124 millones (en 1986) a 1200 (1990) cuando su cifra total alcanzó los 5200 millones y de los que 85 por ciento habían ingresado en el 1986.

La leyenda sobre la Finance One (que a principios de 1996 era la empresa financiera número uno en el país) puede ilustrar claramente, aunque en pequeña escala, la crisis del sector financiero tailandés, debido a que sus métodos prosperaron en lo que algún comentarista de noticias de Bangkok describiese como: "un mercado ascendente que remuneraba generadores de rentas elevadas al tiempo que pasaba por alto los riesgos en la búsqueda de negocios". ${ }^{1}$ La Finance One no solamente se comprometió en actividades tradicionales como el financiamiento de bienes raíces y las ventas sobre la instalación de vehículos de usos diversos, sino que además invirtió grandes sumas en la especulación bursátil adquiriendo bienes, y se hizo de empresas en aprietos o de pequeñas firmas financieras y aseguradoras, para lo que requirió de fuertes préstamos por parte de instituciones financieras del exterior, además de ofertas en el mercado de valores.

En 1996 la mayoría de estos préstamos e inversiones habían comenzado a descomponerse en un grado tal que la dificultad para contenerlos golpeaba ya a todo el país, y el pánico general no se hizo esperar. Las cuentas nacionales aparecidas a principios del año siguiente confirmaron los grandes temores de los inversionistas extranjeros. La deuda externa alcanzó los 89000 millones, de los que 80 por ciento eran deuda privada y poco menos de la mitad eran a corto plazo. La red de responsabilidades de los bancos de Tailandia representaba ahora 20 por ciento del PNB (ver cuadro 1). 
Cuadro 2

Nivel de inequidad de Tailandia con respecto a países seleccionados

\begin{tabular}{lc}
\hline País & Coeficiente de Gini (1) \\
\hline Sierra Leona & 62.9 \\
Brasil & 60.1 \\
Sudáfrica & 58.4 \\
México & 50.3 \\
Malasia & 48.4 \\
Venezuela & 46.8 \\
Ecuador & 46.6 \\
Tailandia & 46.2 \\
Filipinas & 42.9 \\
Indonesia & 34.2 \\
Egipto & 32 \\
Vietnam & 35.7 \\
Pakistán & 31.2 \\
India & 28.7 \\
\hline
\end{tabular}

(1) El coeficiente de Gini mide la extensión de la distribución del ingreso entre individuos o familias dentro de una economía, en relación con la desviación de una distribución perfectamente igualitaria. El índice de Gini cero representaría una perfecta igualdad, mientras que un índice muy alto indica una perfecta inequidad.

Fuente: World Bank, World Development Indicators 1998 (World Bank: Washington, DC, 1998)

Tabla 2.8, p. 70.

Los pilares de la economía sobre los que fueron desplegadas las crisis de los bienes inmuebles y de los sectores financieros de Tailandia no eran sólidos, y se intersectaron con y fueron ampliadas por lo que podría ser descrito como la maduración de los defectos de la economía tailandesa: 1) su tremenda dependencia en el capital extranjero; 2 ) su fuerte dependencia en un frágil sector de exportación (ver cuadro 2 ); 3 ) la tendencia de un alto crecimiento mano a mano con un creciente deterioro de la distribución del ingreso; 4) la erosión de la posición de la agricultura dentro de la economía nacional, y, 5) la enorme prioridad otorgada a las fuerzas del mercado y a un sector privado en desarrollo.

En síntesis, podemos decir que la descendente espiral económica de Tailandia parece haberse convertido en un proceso en el que los aspectos estructurales negativos del modelo de desarrollo de un capitalismo acelerado reforzarían de manera positiva a algún otro.

\section{Nota}

1 K. I. Woo, "Policy makers rethinking merger plans", The Nation, 9 de mayo de 1997, p. 10. 